\title{
Author Correction: Markers of subclinical vascular damages associate with indices of adiposity and blood pressure in obese children
}

\section{Sara Bonafini ${ }^{1}$ - Alice Giontella ${ }^{1}$ - Angela Tagetti ${ }^{1} \cdot$ Denise Marcon $^{1} \cdot$ Martina Montagnana $^{2} \cdot$ Marco Benati $^{2}$. Elisa Danese ${ }^{2} \cdot$ Pietro Minuz $^{1}$. Claudio Maffeis ${ }^{3} \cdot$ Franco Antoniazzi $^{3} \cdot$ Cristiano Fava $^{1}$}

(c) The Japanese Society of Hypertension 2019

Correction to: Hypertension Research, https://doi.org/10.1038/s41440-018-0173-7, published online 9 January 2019
Since the publication of this paper, it has been noted that the author Denise Marcon had been missed out of the author list. The correct author list is shown above.

Sara Bonafini

bonafinisara@gmail.com

Department of Medicine, University of Verona, Verona, Italy

2 Department of Neurosciences, Biomedicine and Movement Sciences, University of Verona, Verona, Italy

3 Department of Surgery, Dentistry, Paediatrics and Gynaecology, University of Verona, Verona, Italy 